\title{
Flow Cytometry of Breast Cancer Resistant Protein and microRNA in Breast Cancer Patients Post Metformin Effect
}

\author{
Bassent Gamal Abdel Nasser Mohammed (MSc) \\ Ashour Abdel Salam Abdel Mawla (Professor)
}

Department of Histochemistry and Cell biology medical research institute, Alexandria University

Sameh Ibrahim Zaki (Professor)

Department of Cancer research and management medical research institute Alexandria University

Mohamed Atteya Saad Atteya (Assistant professor)

Department of Clinical pathology, Faculty of medicine, Tanta University

\begin{abstract}
The goal of the present study is to investigate the role of metformin (MF) as a target of miRNAs in breast cancer resistant protein (BCRP) inhibition in an attempt to develop treatment strategies that may improve the response of breast cancer (BC) patients to chemotherapy (CT). In order to fulfill this target, non-diabetic female subjects were categorized into three groups: control group (group 1) $(n=5)$, CT group of BC patients (group 2) $(n=25)$ and CT plus MF group of BC patients (group 3) $(n=25)$. All patients were subjected to full history taking, laboratory studies including mammogram, chest X-ray, pelvic-abdominal ultrasound and isotopic bone scan, in addition to ER and PR states. CT group was treated with neoadjuvent CT in the form of 5-FU (500 mg/m ${ }^{2}$ ), Adriamycin $\left(50 \mathrm{mg} / \mathrm{m}^{2}\right)$ and cyclophosphamide (500 $\mathrm{mg} / \mathrm{m}^{2}$ ). Flow cytometry (FC) of BCRP and MiRNA was carried out on blood samples at every cycle of treatment for all partners.

The results showed the presence of miRNA was higher than the presence of BCRP in the normal healthy control group. In most cases of CT and CT plus MF groups (group 2, 3) it was well noticed that the amount of BCRP in the blood samples exceeded that of miRNA illustrated the dysregulation of miRNA in BC patients and also to prove the basic role of BCRP as a multidrug resistance (MDR) for chemotherapeutic agents in patients with BC.
\end{abstract}


It is concluded that the role of MF was well proved in targeting of miRNA to reinforce BC medication, so oncologists can be advised to use MF equivalent to $\mathrm{CT}$ in the recommended doses.

Keywords: Breast cancer, Breast cancer resistant protein, Chemotherapy, Flow cytometry, Metformin, Multidrug resistance, microRNAs.

\section{Introduction}

Breast cancer is the most commonly diagnosed cancer and worldwide it is considered the leading cause of cancer death in females, accounting for $23 \%$ (1.38 million) of the total new cancer cases and $14 \%(458,400)$ of the total cancer deaths (Anderson et al., 2008).

Approximately half of the BC cases and $60 \%$ of the deaths are estimated to take place in developing countries, In Egypt, the median age at diagnosis for BC is ten years younger than in the United States and Europe (Omar et al., 2003).Cancer in young is generally more aggressive and results in lower survival rates, making early detection even more crucial and emphasizing the importance to raise BC awareness among young females (Sambanje et al., 2012).

Chemotherapy (CT) plays a key role in the treatment of BC; however, the widespread resistance to CT often results in the treatment failure. Drug resistance to chemotherapeutic agents accounts for treatment failure in more than $90 \%$ of patients with metastatic cancer.

Metformin (MF), the most common first-line drug in the treatment of type-2 diabetes, has been shown in previous studies to reduce BC risk, improve survival, and increase the effectiveness of CT.

The discovery of miRNAs has opened new avenues for BC metastasis research. Several lines of evidence now link miRNA dysregulation to carcinogenesis, progression, chemoresistance and recurrence in several cancers. Many recent studies on BC have clearly demonstrated that miRNAs can play an important role in the multistep process of metastasis, functioning as both activators and suppressors of metastasis by critically regulating various stages of migration and invasion. In BC, the expression levels of several miRNAs are significantly different between normal and cancerous tissues and between BCs of different molecular subtypes with a different prognosis. This study aimed to investigate the role of MF as a target of miRNAs in BCRP inhibition in an attempt to develop treatment strategies that may improve the response of breast cancer patients to chemotherapy. 


\section{Methods}

\section{Subjects}

This study included 55 non-diabetic females aged from 37-70 years old, after written informed consent. Fifty patients were selected with histological proved BC patients admitted to Cancer Research and Management Department, Medical Research Institute, Alexandria University. Five volunteers of apparently normal breast and with comparable characteristics served as control group. Patients were subjected to:

Full history taking thorough clinical examination, laboratory studies including complete blood count, kidney and liver function tests, tumor markers (CEA and CA15.3), radiological examination including mammogram, chest X-ray, pelvic-abdominal ultrasound, isotopic bone scan and estrogen and progesterone receptors states.

\section{Study design and treatment}

Non-diabetic female subjects were categorized in three groups: control group (group1) $(n=5)$, CT group of BC patients (group 2) $(n=5)$ and CT plus MF group of BC patients (group 3) $(n=25)$. Before every cycle of treatment, blood samples from all participants were used to determine the following parameters:

\section{(1) Preparation of blood cells}

Blood was collected from patients in the different groups and blood films were left to air dry. The slides were flood with Leishman's stain solution, wait for 8 minutes and then flood off with distilled water in $2-3$ seconds.

\section{(2) Flow cytometry of BCRP and miRNAs.}

In summary, three tubes were taken, the first was for the negative control; the second was for anti-DDX6/RCK for miRNA and the third was for anti-BCRP.

Red blood corpuscles and platelets were lysed using lysing agent to see the antibodies (Abs) on the white blood corpuscles. 50 $\mu$ of blood were taken and left for 20 minutes. The pellet was formed by vortex centrifuge for 3000 RPM. Wash by PBS after incubation for 30 minutes. The acquisition step was carried out to stop the reaction. The tubes were inserted to 10,000 events cytometer to get the final result sheet, that recorded one negative example and another positive example of the samples required. This was expressed by a dot plot. 


\section{Results}

\section{Patients' characteristics}

\section{A) Leishman's staining}

In normal healthy controls, the basic blood cells are found clearly; In the CT group all blood cells were almost severely damaged. WBCs are burst and RBCs are overlapping at $1^{\text {st }}$ cycle, $2^{\text {nd }}$ cycle, and $3^{\text {rd }}$ cycle of treatment. As for the MF group notable improvements were seen in which the neutrophils were retained with MF treatment and the biconcave shape of RBCs was greatly maintained gradually at $1^{\text {st }}$ cycle $2^{\text {nd }}$ cycle and $3^{\text {rd }}$ cycle.

\section{B) Flow cytometric analysis of BCRP and MicroRNA}

The current study clarified that the values of BCRP at the third dose of $(\mathrm{CT}+\mathrm{MF})$ group was still higher than normal group but these values were less than that of (CT) group. This revealed the basic role of BCRP as multidrug resistant although MF succeeded, to some extent in reducing these values (Table 1).

Table 2 displayed that MF at the third dose of treatment regained the normal value for miRNA (mean \pm SD: 49.92 and median: 49.47), A statistical significant conclusion was recorded for the third group (CT + MF) exhibiting that MF had its role in reducing miRNA. This decrease in miRNA in turn represented the refinements in this group as a result of MF targeting miRNA.

Statistically in table 3, it had been shown that correlations existed between BCRP and MiRNA expressions and patients' outcome especially after MF medication. 
Table 1. Comparison between the studied groups according to BCRP

\begin{tabular}{|c|c|c|c|c|c|c|c|c|c|}
\hline & \multirow{2}{*}{$\begin{array}{l}\text { Control } \\
\text { group } \\
(\mathbf{n}=5)\end{array}$} & \multicolumn{3}{|c|}{ CT group (doses) } & \multicolumn{3}{|c|}{ MF group (doses) } & \multirow[b]{2}{*}{$\mathbf{F}$} & \multirow[b]{2}{*}{$\mathbf{p}$} \\
\hline & & $\begin{array}{c}1^{\text {st }} \\
(n=25)\end{array}$ & $\begin{array}{c}2^{\text {nd }} \\
(n=25)\end{array}$ & $\begin{array}{c}3^{\mathrm{rd}} \\
(\mathrm{n}=25)\end{array}$ & $\begin{array}{c}1^{\text {st }} \\
(n=25)\end{array}$ & $\begin{array}{c}2^{\text {nd }} \\
(n=25)\end{array}$ & $\begin{array}{c}3^{\mathrm{rd}} \\
(\mathrm{n}=25)\end{array}$ & & \\
\hline BCRP \% & & & & & & & & & \\
\hline Min. - Max. & $1.05-50.34$ & $\begin{array}{l}66.22- \\
98.13\end{array}$ & $\begin{array}{l}66.17- \\
98.12\end{array}$ & $\begin{array}{l}66.13- \\
98.04\end{array}$ & $\begin{array}{l}52.53 \pm \\
88.10\end{array}$ & $\begin{array}{l}44.98- \\
77.05\end{array}$ & $\begin{array}{l}44.15- \\
59.26\end{array}$ & & \\
\hline Mean \pm SD. & $26.29 \pm 2.55$ & $83.59 \pm 9.74$ & $83.46 \pm 9.68$ & $83.03 \pm 9.68$ & $63.54 \pm 6.93$ & $60.59 \pm 8.35$ & $51.87 \pm 3.24$ & $71.327^{*}$ & $<0.001^{*}$ \\
\hline Median & 27.18 & 85.65 & 85.60 & 85.59 & 66.13 & 60.86 & 51.16 & & \\
\hline $\mathbf{p}_{1}$ & & $<0.001^{*}$ & $<0.001^{*}$ & $<0.001^{*}$ & $<0.001^{*}$ & $<0.001^{*}$ & $<0.001^{*}$ & & \\
\hline $\mathbf{p}_{2}$ & & & & & $<0.001^{*}$ & 0.866 & $<0.001^{*}$ & & \\
\hline
\end{tabular}

F: F test (ANOVA)

$\mathrm{p}_{1}$ : $\mathrm{p}$ value for Post Hoc test (LSD) for comparing between control and each other group

$\mathrm{p}_{2}$ : $\mathrm{p}$ value for Post Hoc test (LSD) for comparing between CT group $1^{\text {st }}$ with MF group $1^{\text {st }}$, CT group $2^{\text {nd }}$ with MF group $2^{\text {nd }}$ and CT group $3^{\text {rd }}$ with MF group $3^{\text {rd }}$

*: Statistically significant at $\mathrm{p} \leq 0.05$ 
Table 2. Comparison between the studied groups according to MiRNA

\begin{tabular}{|c|c|c|c|c|c|c|c|c|c|}
\hline & \multirow{2}{*}{$\begin{array}{c}\text { Control } \\
\text { group } \\
(n=5)\end{array}$} & \multicolumn{3}{|c|}{ CT group (doses) } & \multicolumn{3}{|c|}{ MF group (doses) } & \multirow[b]{2}{*}{$\mathbf{F}$} & \multirow[b]{2}{*}{$\mathbf{p}$} \\
\hline & & $\begin{array}{c}1^{\text {st }} \\
(n=25)\end{array}$ & $\begin{array}{c}2^{\text {nd }} \\
(n=25)\end{array}$ & $\begin{array}{c}3^{\mathrm{rd}} \\
(\mathrm{n}=25)\end{array}$ & $\begin{array}{c}1^{\text {st }} \\
(n=25)\end{array}$ & $\begin{array}{c}2^{\text {nd }} \\
(n=25)\end{array}$ & $\begin{array}{c}3^{\text {rd }} \\
(n=25)\end{array}$ & & \\
\hline \multicolumn{10}{|l|}{ MiRNA \% } \\
\hline \multirow{3}{*}{$\begin{array}{l}\text { Min. - Max. } \\
\text { Mean } \pm \text { SD. } \\
\text { Median }\end{array}$} & \multirow{3}{*}{$\begin{array}{c}43.56- \\
55.96 \\
49.36 \pm \\
5.59 \\
49.0\end{array}$} & \multirow{3}{*}{$\begin{array}{c}59.27- \\
93.42 \\
76.69 \pm \\
10.13 \\
77.09\end{array}$} & \multirow{3}{*}{$\begin{array}{c}59.20- \\
93.40 \\
76.58 \pm \\
10.12 \\
76.92\end{array}$} & \multirow{3}{*}{$\begin{array}{c}59.0- \\
93.14 \\
76.21 \pm \\
10.21 \\
76.61\end{array}$} & \multirow{3}{*}{$\begin{array}{c}40.22- \\
64.76 \\
55.37 \pm \\
7.99 \\
59.24\end{array}$} & \multirow{3}{*}{$\begin{array}{c}40.90- \\
62.17 \\
54.05 \pm \\
6.66 \\
55.43\end{array}$} & \multirow{3}{*}{$\begin{array}{c}43.16- \\
59.72 \\
49.92 \pm \\
4.62 \\
49.47\end{array}$} & \multirow{3}{*}{$\begin{array}{l}51.0 \\
65^{*}\end{array}$} & \multirow{3}{*}{$<0.001^{*}$} \\
\hline & & & & & & & & & \\
\hline & & & & & & & & & \\
\hline $\mathbf{p}_{1}$ & & $<0.001^{*}$ & $<0.001^{*}$ & $<0.001^{*}$ & 0.150 & 0.261 & 0.893 & & \\
\hline $\mathbf{p}_{2}$ & & & & & $<0.001^{*}$ & $<0.001^{*}$ & $<0.001^{*}$ & & \\
\hline
\end{tabular}

\section{F: F test (ANOVA)}

$\mathrm{p}_{1}$ : $\mathrm{p}$ value for Post Hoc test (LSD) for comparing between control and each other group

$\mathrm{p}_{2}$ : $\mathrm{p}$ value for Post Hoc test (LSD) for comparing between CT group II $1^{\text {st }}$ with MF group III $1^{\text {st }}$, CT group II $2^{\text {nd }}$ with MF group III $2^{\text {nd }}$ and CT group II $3^{\text {rd }}$ with MF group III $3^{\text {rd }}$

*: Statistically significant at $\mathrm{p} \leq 0.05$

Table 3. Correlation between BCRP with MiRNA in each studied group

\begin{tabular}{|c|c|c|}
\hline \multirow{2}{*}{ BCRP } & \multicolumn{2}{|c|}{ MiRNA } \\
\hline & $\mathbf{r}$ & $\mathbf{p}$ \\
\hline Control & 0.128 & 0.838 \\
\hline Group II $1^{\text {st }}$ dose CT & $0.508^{*}$ & 0.010 \\
\hline Group II $2^{\text {nd }}$ dose CT & $0.514^{*}$ & 0.009 \\
\hline Group II $3^{\text {rd }}$ dose CT & $0.517^{*}$ & 0.008 \\
\hline Group III 1 ${ }^{\text {st }}$ dose CT + MF & $0.644^{*}$ & 0.001 \\
\hline Group III $2^{\text {nd }}$ dose CT + MF & 0.328 & 0.109 \\
\hline Group III $3^{\text {rd }}$ dose CT + MF & 0.249 & 0.231 \\
\hline
\end{tabular}

r: Pearson coefficient

*: Statistically significant at $\mathrm{p} \leq 0.05$ 


\section{C) Flow cytometric analysis of results by dot plot}

\section{Flow cytometric results of BCRP}

i) The control group $(n=5)$
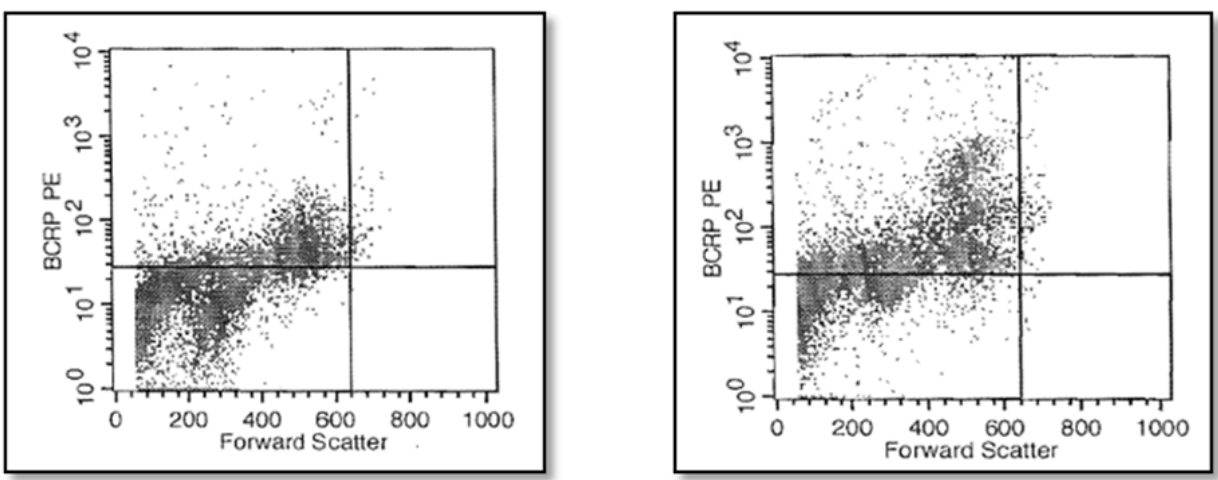

ii) The CT group $(\mathrm{n}=25)$

a) At the first cycle of treatment
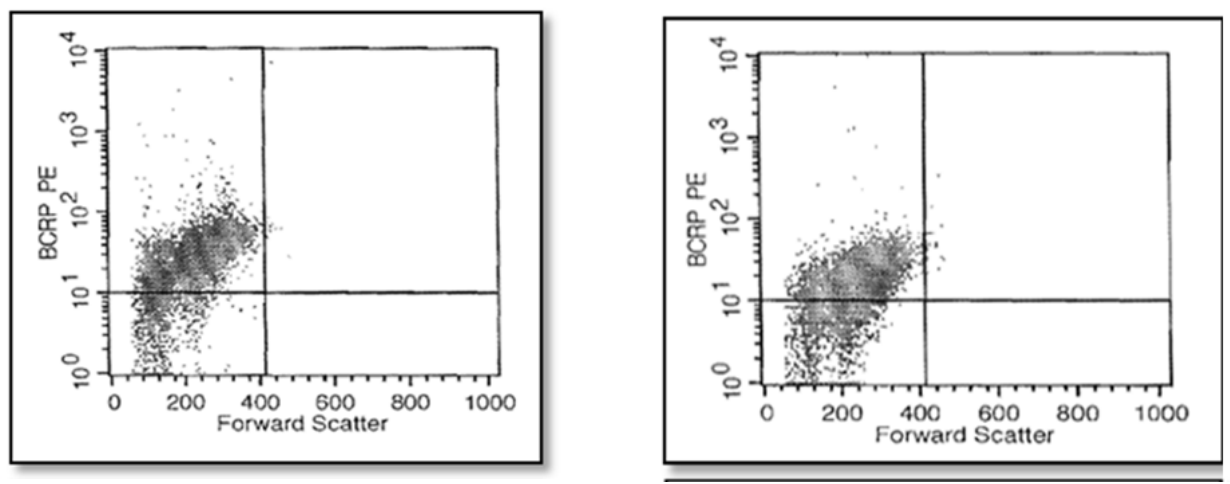

b) At the second cycle of treatment
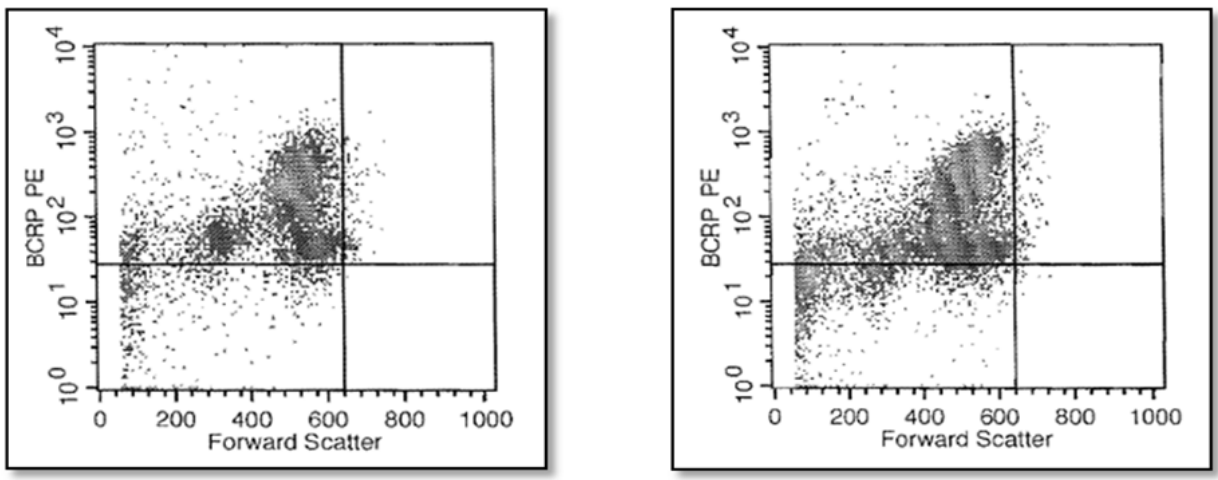
c) At the third cycle of treatment

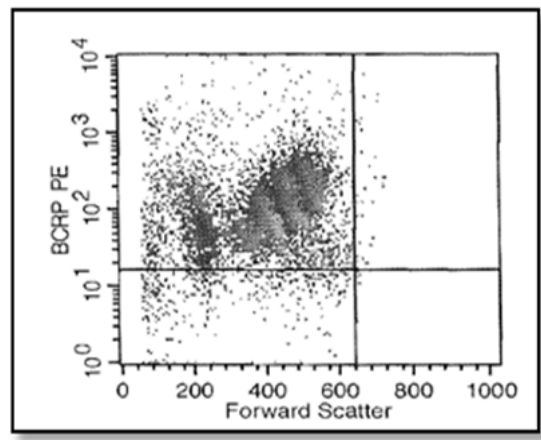

iii) The CT plus MF group ( $\mathrm{n}=25)$

a) At the first cycle of treatment

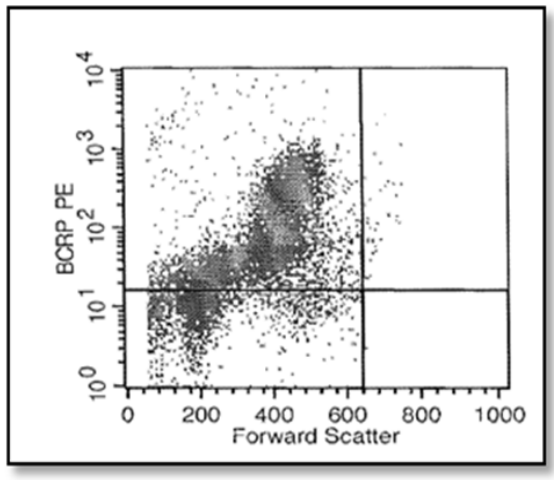

b) At the second cycle of treatment

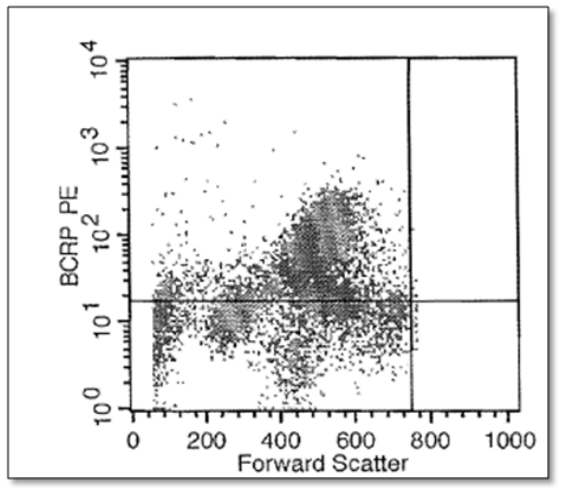

c) At the third cycle of treatment
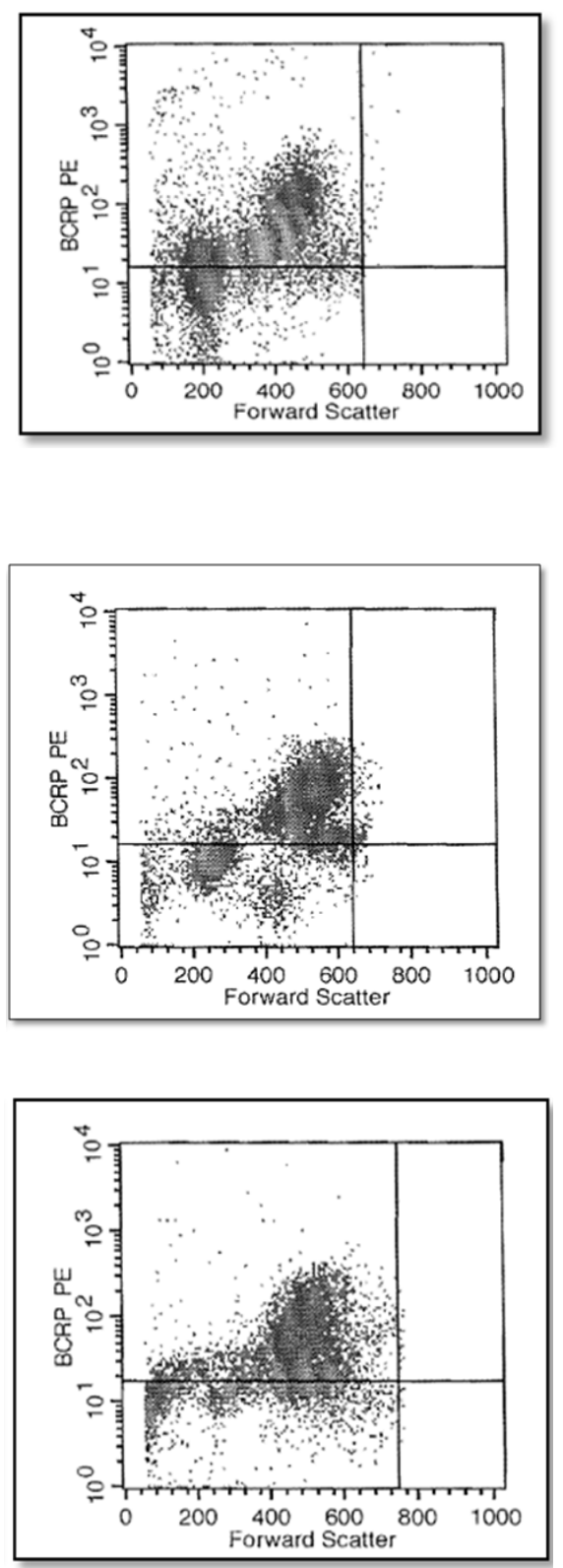

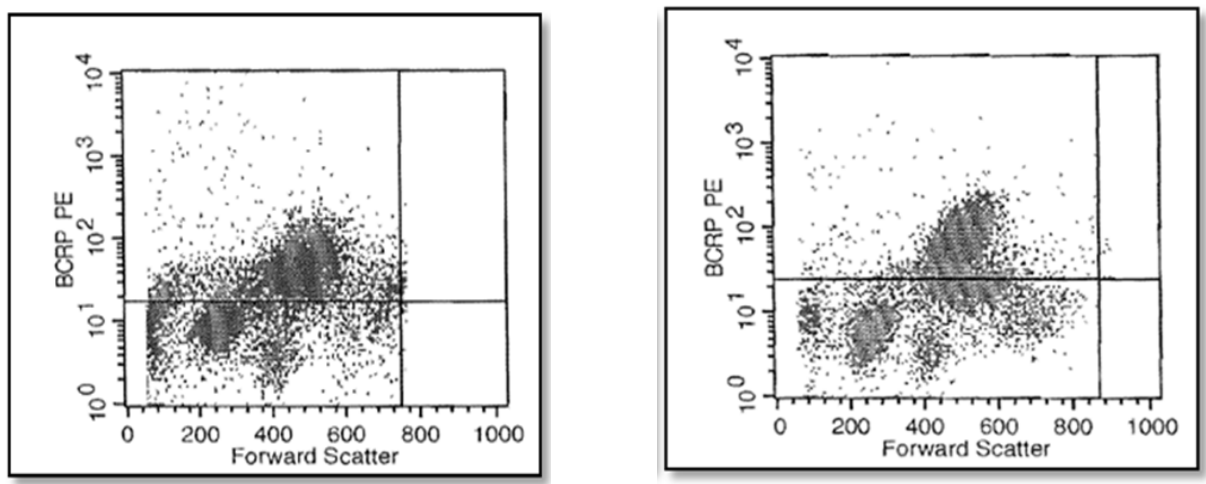

\section{Flow cytometric results of miRNA}

i) The control group $(n=5)$
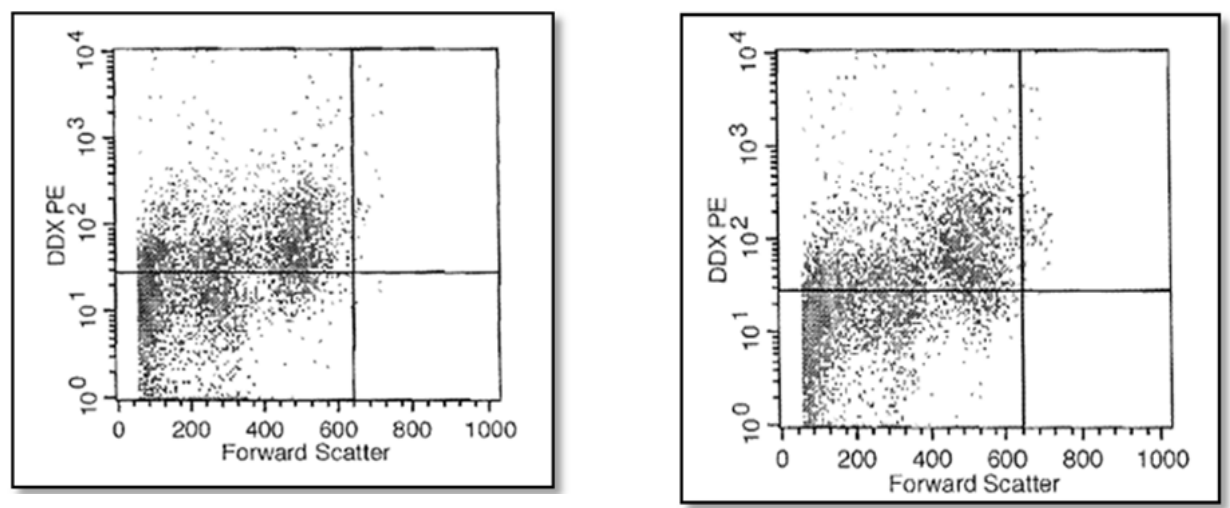

ii) The CT group $(\mathrm{n}=25)$

a) At the first cycle of treatment
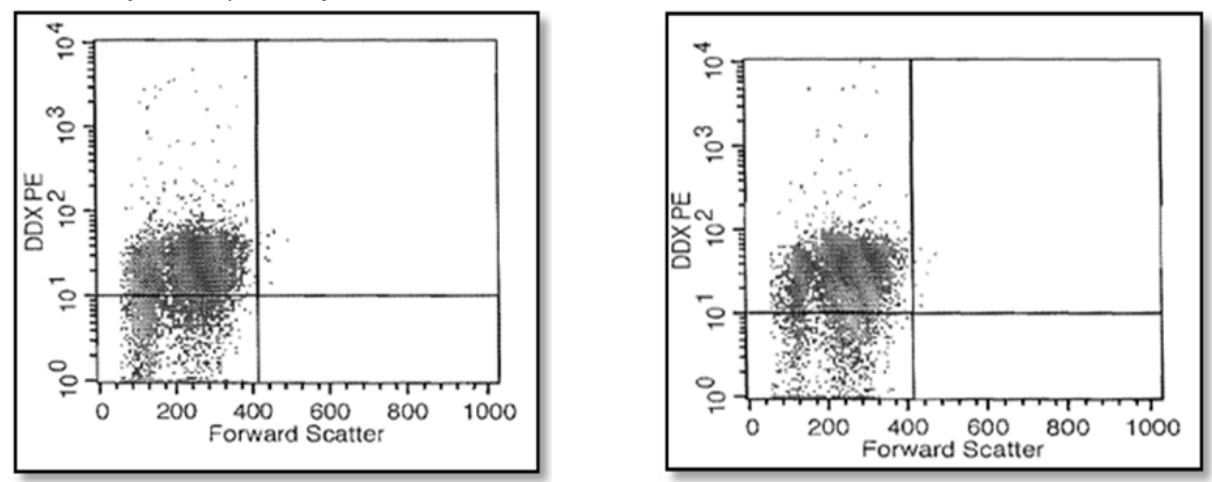

b) At the second cycle of treatment 


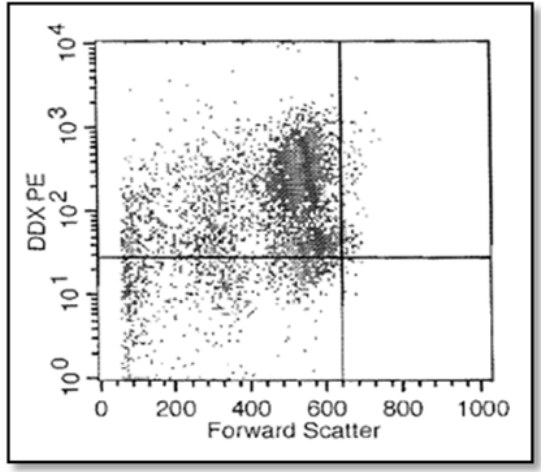

c) At the third cycle of treatment

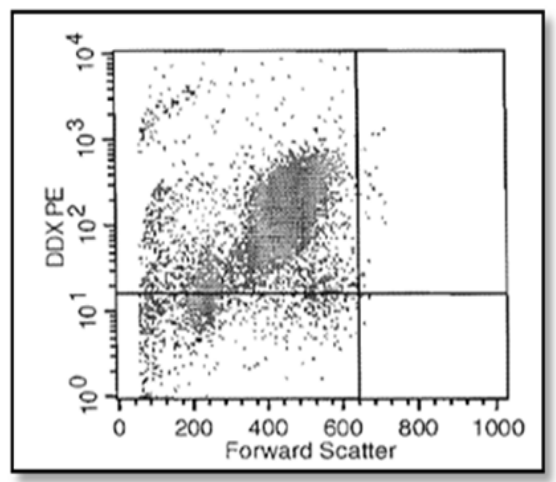

iii)The CT plus MF group ( $\mathrm{n}=25)$

a) At the first cycle of treatment

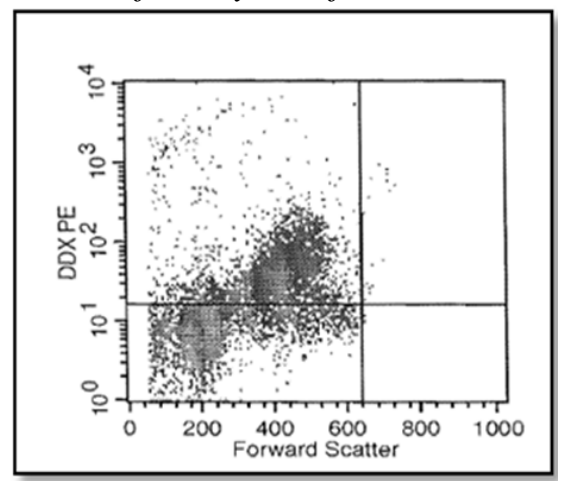

b) At the second cycle of treatment
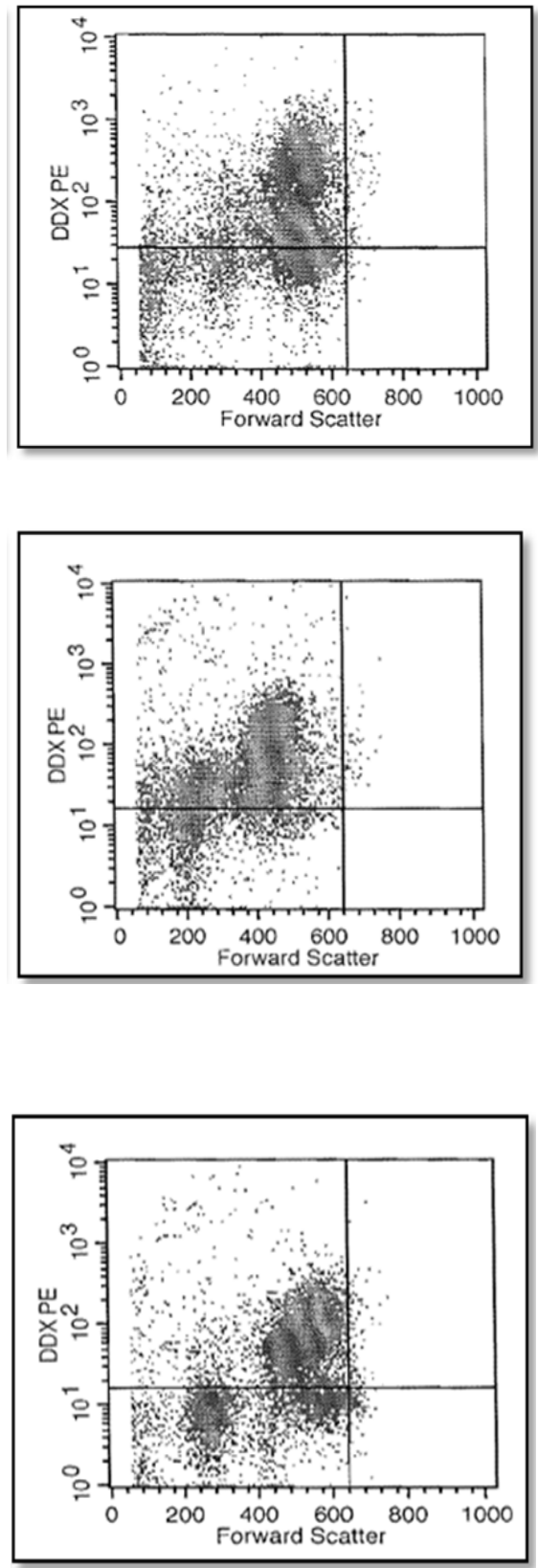

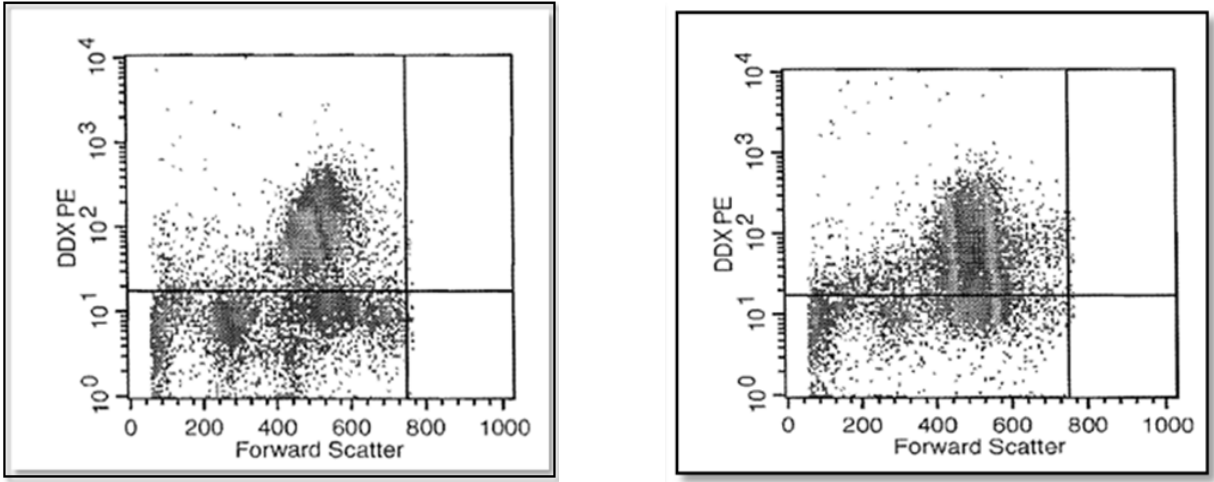

c) At the third cycle of treatment
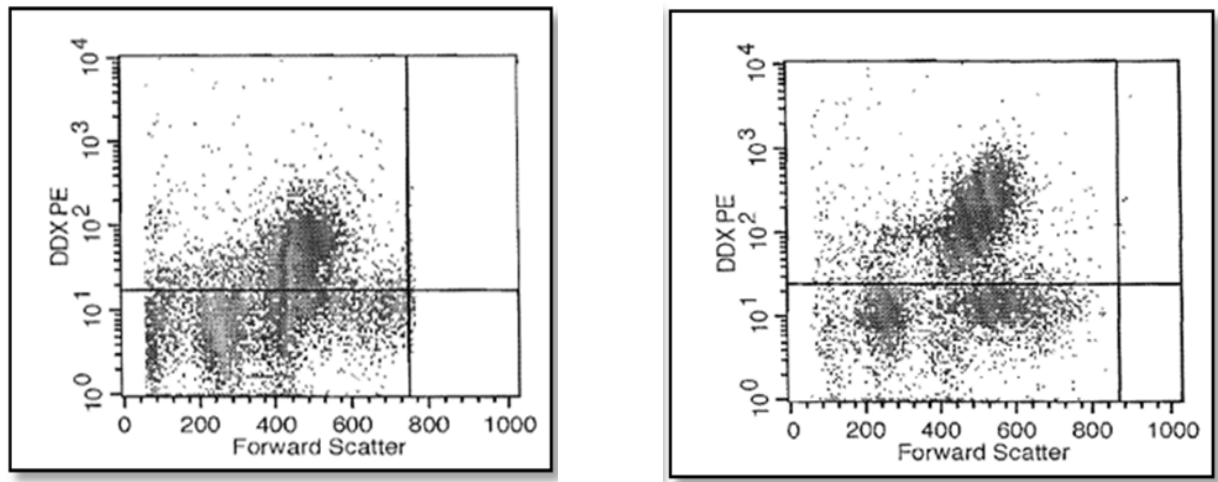

\section{Discussion}

$\mathrm{BC}$ is a major health problem that will affect approximately 1.3 million women worldwide. In 2013 the American cancer society, estimated that more than 296,000 women and 2,240 men were diagnosed with BC, Recently, researchers at the NCI projected that the overall BC incidence rate will stay the same through 2016. CT plays a key role in the treatment of BC; however, the widespread resistance to CT often results in the treatment failure. Drug resistance to chemotherapeutic agents accounted for treatment failure in more than $90 \%$ of patients with metastatic cancer.

Previous studies indicated that BCRP conferred an atypical MDR phenotype. A transfectant BCRP expression cell model was established and utilized to screen clinical anticancer drugs in vitro. In addition, BCRP expression was reported in 20-30\% of clinical BC tissue specimens. A recent result suggested that BCRP expression may contribute to the failure of BC CT to a certain extent.

The present results showed that the control group had the lowest values for BCRP (mean: 26.29). The (CT) group had the highest values (mean: 83.03) after the third cycle and near this value post first and second doses. The MF group situated between the lowest and highest values (mean 51.87) 
after third cycle. These values indicated the basic role of BCRP as MDR and reflected, in addition the success of MF in amelioration of elevated values of BCRP in the third group (CT + MF).

Present results were coincided with many literatures that revealed increased values for BCRP either in BC or in other types of cancers. Current results were coincided with this consideration stating that the occurrence of BCRP is higher in BC patients group (CT) than control group. But after the MF treatment this group demonstrated lower expression due to MF's indirect effect on the role of BCRP as a drug resistant.

With respect to miRNAs, these compounds are evolutionarily conserved, endogenous, single-stranded, noncoding RNA molecules that are reported to be involved in many biological processes, including cell proliferation, apoptosis, and tumorigenesis, through their regulation of gene expression. Most miRNAs bind to target sequences located within the 3'UTR of mRNAs by base pairing, resulting in the cleavage of target mRNAs or repression of their translation.

Regarding present results, the same values of miRNA were more or less observed in both normal and (CT + MF) groups (mean: 49.36 and 49.92 and the median: 49.0 and 49.47 respectively). The elevated miRNA values were recorded in second group (CT) at all cycles. These values indicated that the MF revealed its role in reducing miRNA, which in turn represented the improvements in this group (CT + MF) and this amelioration was dosedependent. These results were coincided with previous reports elucidated.

Eventually miRNAs which are found intracellularly and extracellularly are functioning in mainly the regulation of gene expression, apoptosis and tumorigenesis. Moreover, the recent role of miRNAs in BC is diagnosis and treatment.

Since miRNAs were dysregulated in both normal and malignant tissues of the breast and other body fluids. Therefore their expression was varying in the same tissue with levels up and down and sometimes vice versa with respect to previous studies. So the amount of miRNA in control group was lower than that of the patients groups (group CT \& MF). In addition miRNAs act as oncogenes and tumor suppressor genes and vice versa inside the cell under certain circumstances. In current results, this dysregulation of miRNA was clearly noted. Before the treatment with MF in the (CT) group miRNAs expression was found in a higher level that could be due to miRNA biogenesis pathways, in which the Cis regulation targeting of mRNA is done so in this situation the occurrence of miRNAs was highly found in the results as they may be oncogenes.

On the other hand after the addition of MF medication, MF could acts as a miRNA inhibitor. In this situation the occurrence of miRNAs was found in $(\mathrm{CT}+\mathrm{MF})$ group to be lower than the $(\mathrm{CT})$ group only. This reduction in 
miRNA may reflect its role as tumor suppressor gene instead of oncogene. This in turn highlighted the role of MF in targeting miRNA.

Finally the role of MF was well illustrated in targeting of miRNA to reinforce BC medication. In conclusion we can advise oncologists to use MF equivalent to $\mathrm{CT}$ in the recommended doses. MF led to a significant reduction in untoward effect of CT and cancer and improved the patients' outcome which may be due to its role as selectively killer for the cells that were chemoresistant.

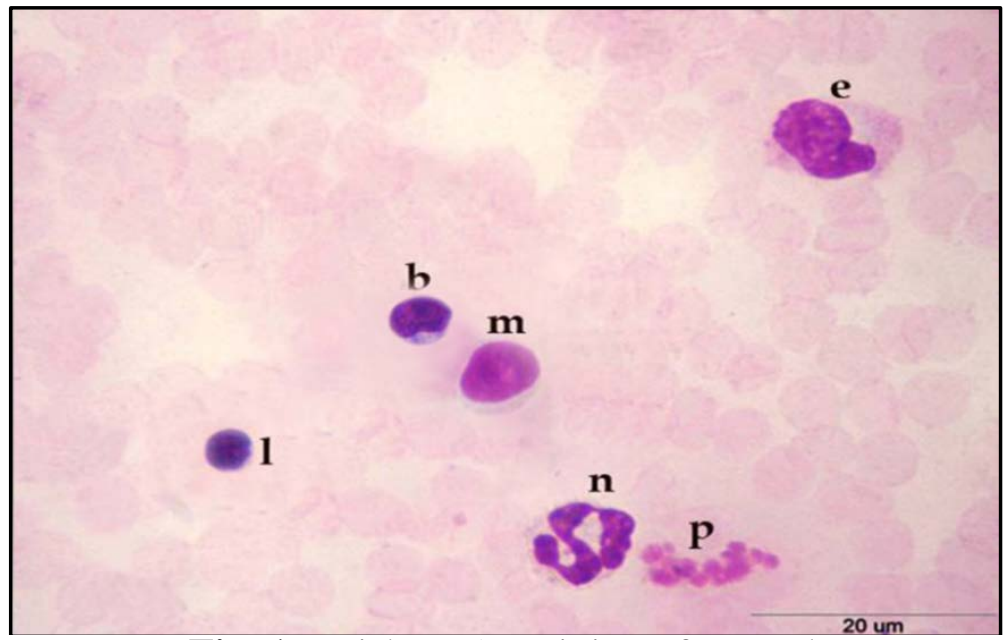

Fig. 1: Leishman's staining of control groupX1000(e:eosinophil,b:basophil,m:monocyte,l:lymphocyte,n:neutrophil, p:platelets).

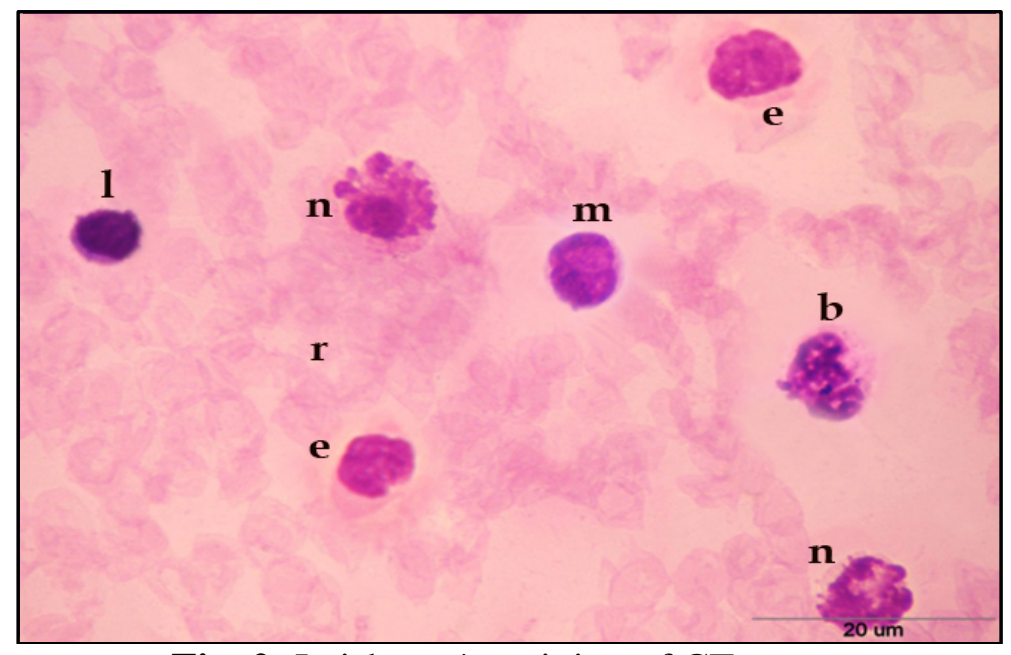

Fig. 2: Leishman's staining of CT group

X1000(e:eosinophil,b:basophil,m:monocyte,l:lymphocyte,n:neutrophil,p:plat elets,r:rbcs). 


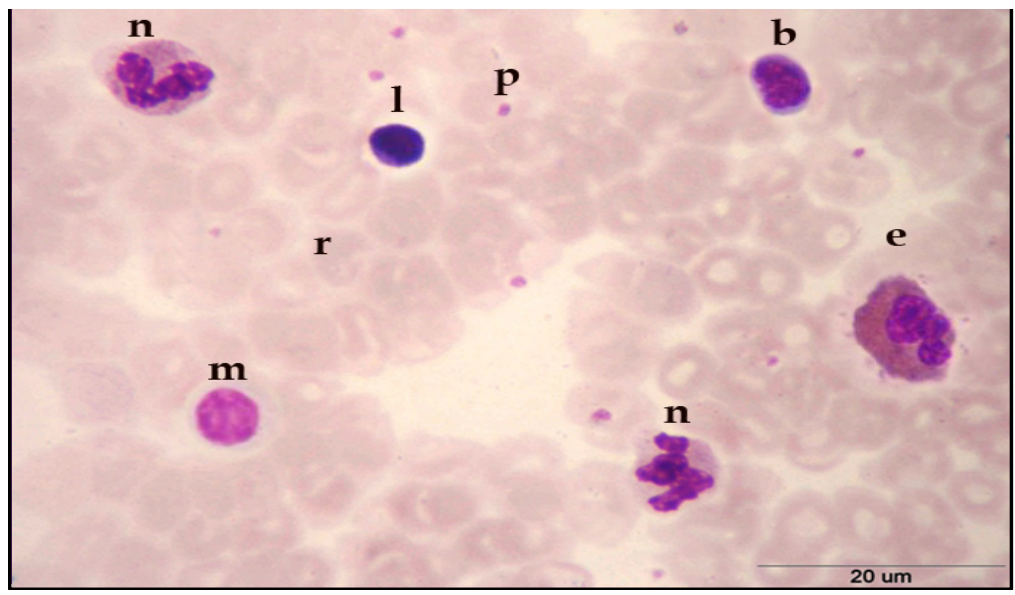

Fig. 3: Leishman's staining of MF group

X1000(e:eosinophil,b:basophil,m:monocyte,l:lymphocyte,n:neutrophil,p:plat elets,r:rbcs).

\section{References:}

1. Anderson BO, Yip $\mathrm{CH}$, Smith $\mathrm{RA}$, et al. Guideline implementation for breast healthcare in low-income and middleincome countries: overview of the Breast Health Global Initiative Global Summit 2007. Cancer. 2008 ; 113: 2221-43.

2. Dina N. K. Boulos, Ramy R. Ghali. Awareness of Breast Cancer among Female Students at Ain Shams University, Egypt.Global Journal of Health Science.2014; (6)1.

3. Omar S, Khaled H, Gaafar R, Zekry A R, Eissa S, El-Khatib, O. Breast cancer in Egypt: A review of disease presentation and detection strategies. East Mediterr Health J.2003; 9: 448-463.

4. Sambanje MN, Mafuvadze B. Breast cancer knowledge and awareness among university students in Angola. Pan Afr Med J.2012; 11: 70 .

5. Grim J, Jandík P, Slánská I. Low expression of NQO1 predicts pathological complete response to neoadjuvant chemotherapy in breast cancer patients treated with TAC regimen. Folia Biol (Praha). 2012; 58:185-92.

6. Longley DB, Johnston PG. Molecular mechanisms of drug resistance. J Pathol. 2005; 205: 275-92.

7. Reema WA, Zeying F, Susan M E, Bolin L, Xin-Sheng D, Sigrid S A, et al. Glucose promotes breast cancer aggression and reduces metformin efficacy. Cell Cycle.2013.

8. Athina M, George M, Yousef E S, Vassilis G. Prognostic Significance of Metastasis-Related MicroRNAs in Early Breast 
Cancer Patients with a Long Follow-up Clinical Chemistry.2014; 60(1): 197-205.

9. Sarkar FH, Li Y, Wang Z, Kong D, Ali S. Implication of microRNAs in drug resistance for designing novel cancer therapy. Drug Resist Update. 2010; 13: 57-66.

10. Liang YJ, Wang QY, Zhou CX, Yin QQ, He M, Yu XT, et al. MiR124 targets Slug to regulate epithelial mesenchymal transition and metastasis of breast cancer. Carcinogenesis 2013; 34:713-22.

11. Vander AI, Limame R, van Dam P, Vermeulen PB, Dirix LY, Van Laere SJ. Integrated miRNA and mRNA expression profiling of the inflammatory breast cancer subtype. Br J Cancer. 2010; 103: 532 41.

12. Tavazoie SF, Alarcon C, Oskarsson T, Padua D, Wang Q, Bos PD, et al. Endogenous human microRNAs that suppress breast cancer metastasis. Nature. 2008; 451: 147- 52.

13. Lewis SM, Brain BJ, Bates I. Daice and Lewis Practical Hematology $10^{\text {th }}$ ed. Churchill Livingstone Elsevier, Philadelphia. 2006, pp. 40-57(CBC).

14. Burtis CA, Ashwood ER, Burns DE. Tietz Fundamentals of Clinical Chemistry. $6^{\text {th }}$ ed. Elsevier Saunders Company, St Louis.2008, pp. 363-8 (urea, creatinine), 323-5 (AST, ALT), 351-4 (CEA, CA 15.3).

15. Libby G, Donnelly LA, Donnan PT, Alessi DR, Morris AD, Evans JM. New users of metformin are at low risk of incident cancer: a cohort study among people with type 2 diabetes. Diabetes Care. 2009; 32:1620-5.

16. Grundy M, Seedhouse C, Russell HN, Pallis M. P-glycoprotein and breast cancer resistance protein in acute myeloid leukemia cells treated with the Aurora-B Kinase Inhibitor barasertib-hQPA. BMC Cancer. 2011; 11: $254-67$.

17. Blenkiron C, Goldstein LD, Thorne NP, Spiteri I, Chin S-F, Dunning $\mathrm{MJ}$, et al. MicroRNA expression profiling of human breast cancer identifies new markers of tumor subtype. Genome Biol. 2007; 8: 214 -45 .

18. Anderson W, Katki H, Rosenberg P. Incidence of breast cancer in the United States: Current and future trends. J Natl Cancer Inst. 2011; 103(18): 1397- 402.

19. Jemal A, Siegel R, Xu J, Ward E. Cancer Statistics 2010. CA Cancer J Clin. 2010; 60(5): 277-300.

20. Longley DB, Johnston PG. Molecular mechanisms of drug resistance. J Pathol. 2005; 205: 275 - 92.

21. Mohan H. Pathology Practical Book. $2^{\text {nd }}$ Ed. Jaypee brothers. India. 2007, p.188. 
22. Bates SE, Robey R, Miyake K, Rao K, Ross DD and Litman T: The role of half-transporters in multidrug resistance. $\mathrm{J}$ Bioenerg Biomembr. 2001; 33: 503 - 11.

23. Wang M, Wang X, Yuan J, Guo L. Expression of the breast cancer resistance protein and 5-fluorouracil resistance in clinical breast cancer tissue specimens. Mole clinoncol. 2013; 1: 853 - 7.

24. Yuan JH, Zhou JM, Ji N. Epigenetic regulation mechanism of ABCG2 induced drug-resistant phenotype. J Med Coll PLA. 2011; 26: $243-53$.

25. Faneyte IF, Kristel PM, Maliepaard M, Scheffer GL, Scheper RJ, Schellens JH , et al. Expression of the breast cancer resistance protein in breast cancer. Clin Cancer Res. 2002; 8: 1068 - 74.

26. Yoh K, Ishii G, Yokose T, Minegishi Y, Tsuta K, Goto K, et al. Breast cancer resistance protein impacts clinical outcome in platinum-based chemotherapy for advanced non-small cell lung cancer. Clin Cancer Res. 2004; 10 (5): 1691 - 7.

27. Kanzaki A, Toi M, Nakayama K, Bando H, Mutoh M, Uchida T. Expression of multidrug resistance-related transporters in human breast carcinoma. Jpn J Cancer Res. 2001; 92: 452 - 8.

28. Ambros V. The functions of animal microRNAs. Nature. 2004; 431: $350-5$.

29. Hadad SM, Dewar JA, El seedawy E, Jordan LB, Purdie C, Bray SE, et al. Gene Signature of metformin actions on primary breast cancer within a window of opportunity randomized clinical trial. J ClinOncol. 2010; 28 (15): 560.

30. Schwarzenbacher D, Balic M, Pichler M. The Role of MicroRNAs in Breast Cancer Stem Cells. Int. J MolSci. 2013; 14: 14712 - 23.

31. Esquela-Kerscher A, Slack FJ. Oncomirs - microRNAs with a role in cancer. Nat Rev Cancer. 2006; 6: 259 - 69.

32. Wang D, Qiu C, Zhang H, Wang J, Cui Q, et al. Human MicroRNA Oncogenes and Tumor Suppressors Show Significantly Different Biological Patterns: From Functions to Targets. PLoS ONE. 2010; 5(9): 13067.

33. Ruan K, Fang X, Ouyang G. MicroRNAs: Novel regulators in the hallmarks of human cancer. Cancer Letters. 2009; 285:116 - 26.

34. American Cancer Society. Inc, 2013. 